\title{
The edges of environmental history: an international tribute to the work of Jane Carruthers
}

\author{
$O P-E D$
}

$B Y$

\author{
FILIPA SOARES ${ }^{1}$
}

In an unprecedented international tribute, a special one-day workshop has been held in Munich to honour the work and influence of South African environmental historian Jane Carruthers, President of the International Consortium of Environmental History Organisations (ICEHO). The event was organized by the Rachel Carson Center for Environment and Society (RCC) at Ludwig Maximilian University (LMU), the largest Center for Advanced Study in the field of the Environmental Humanities. Jane Carruthers has been the Chair of the Academic Board of the Carson Center since its founding in 2009 and she was instrumental, according to RCC director Christof Mauch, in guiding the Carson Center in a spirit of transnational collaboration and interdisciplinary exploration.

Inspired by Carruthers' ground-breaking histories of national parks and biographies of nineteenth century artist-explorers who worked across seas and continents, Christof Mauch (RCC), and Libby Robin (Australian National University and National Museum of Australia) explored, what Robin called, the "edges" of environmental history which ultimately help us see connections: connections between national politics and nature conservation, between environmental inequalities and dominant metaphors for nature, but also geographical connections between literary and colonial histories, carried through maps, biographies, letters, and the transnational flow of people, ideas, and goods.

The workshop was attended by 95 scholars from 30 different countries. Sixteen working papers were presented by eminent environmentalists and historians. All of them emphasized the vision that Professor Carruthers' work had provided them with. The papers will be published in a book entitled The Edges of Environmental History, as well as the paintings by Mandy Martin specifically conceived for this event. The book is expected to be launched at the Second World Congress of Environmental History in Guimarães, Portugal, in July 2014.

Christof Mauch, RCC director and President of the European Society for Environmental History (ESEH), opened the workshop with a description of the work and future of the Center, whose Advisory Board is chaired by Jane Carruthers, and a presentation of the philosophy behind the event and the book. Libby Robin of the Australian National University followed with an introduction to Jane Carruthers and the book Inflows: The Channel County, by Mandy Martin, Jane Carruthers, Guy Fitzhardinge, Tom Griffiths, and Peter Haynes. According to her, this is an example of a successful partnership and collaborative work between artists, scientists and environmental historians.

1 Rachel Carson Center for Environment \& Society, Ludwig-Maximillian Universität München, Germany. 
This idea of collaboration was used In Jane Carruthers' own introductory remarks, seizing the opportunity to thank her colleagues and audience for making environmental history "the most collaborative discipline in the world". She then identified some of the many "edges" that it can introduce, using the examples of Greg Dening and Rachel Carson, and spoke about protected areas and their edges. Carruthers explained how environmentalism, while differing in some respects in South Africa due to the social and political context, nonetheless resonated in other emerging economies. She stressed the importance of a transnational framework within environmental history, namely in the South African context, without forgetting the environmental, political, economic and social specificities of the emerging world. She concluded by mentioning that environmental history could become one of the most important and relevant fields, particularly in the emerging world, with the possibility to broaden the horizons and boundaries of historical study and to provide a reinterpretation of our understanding of historical processes.

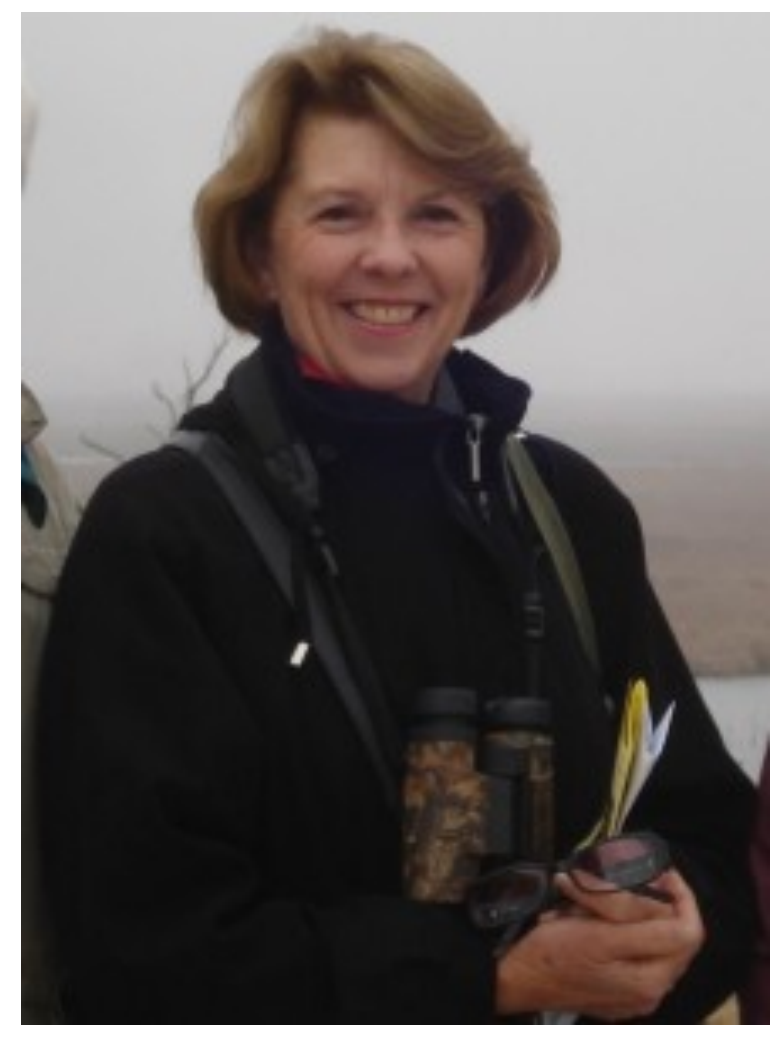

Jane Carruthers

Speakers were grouped into four panels, the first of which, entitled "Inside and Out", centred around Carruthers' emphasis on identifying and analysing differences in how protected areas and nature are perceived.

Kate Christen spoke of her work with wild horses (the extinct and reified Przewalsky's horse) at the Smithsonian Conservation Biology Institute, aiming to analyse distinct experiences of a wildlife species variously located in zoos, protected areas and reintroduction sites. These horses are now used extensively in re-wilding programs, but they have paradoxically been rebred after extinction. Although they are valued as 'wild', they have had extensive breeding programs and their genetic lineage is recorded in studbooks.

Bernhard Gißibl of the Leibniz-Institute für Europäische Geschichte suggested looking at environmentalism and conservation through the lens of cosmopolitics, a concept that applies 
particularly to the global history of national parks. In his presentation, Gißibl provided details of the Frankfurt Zoological Society as an example and suggested a commodity chain analysis of NGO-mediated conservation that includes the multiplicity of worlds (and worldviews) we are confronted with, and whose diverse articulations need to be taken into account for conservation to succeed in practice.

In a similar line of thought, Clapperton Mavhunga, Massachusetts Institute of Technology, took the example of vaShona, the predominant cultural-linguistic group in Zimbabwe, and explored the concept of "nature" from the point of view of African meanings and practices. According to him, these practices are seldom interpreted by "outsiders" in economic and legal terms as poaching, disregarding the underlying cosmovision where nature and culture are not perceived as different entities. This often leads to conflicts. By giving several examples of symbolic uses of animals, he stressed the importance of "wearing a villager's lenses and see what trees, animals, rocks, rivers, and being in them means".

Emily Wakild, Boise State University, described the edginess of Jane Carruthers's history of the Kruger National Park and how it influenced historians' views of what was natural and what was national about national parks, focussing attention on parks as places worthy of study by themselves as well as rich cultural, social, political, and historical 'mirrors'. It also drew attention to transnational knowledge networks, and opened the door to understanding claims of environmental justice and injustice by looking at the larger picture and acknowledging that the same forces that threaten the conservation of natural spaces also threaten the conservation of indigenous cultures.

In a delightful inter-panel presentation, Tom Griffiths (Australian National University) presented an essay about $L a$ Bête du Gérvaudan, the legendary wolf that terrorised France in the mid-eighteenth century and that became a national sensation, serving the interests of urban, educated elites that afterwards attributed the legend to rural superstition. Through this example, he reflected about how the wild is negotiated, and the importance to look at the social, ecological and historical context of its making. He ended with a thought-provoking twist comparing the eighteenth century prejudices of rural France with latter-day attitudes to natural phenomena such as the destructive fires of Australian forests.

Recalling Claude Lévi-Strauss' famous dictum, the second panel was entitled “Thinking with Wild Animals" and was focused on perceptions and attitudes towards wildlife.

Thomas Dunlap, Texas A\&M University, demonstrated how birds and birding have provided the bridges to the world outside and to our relation to it, shaping not only action but also individual consciousness. Birds, because of their familiarity and proximity to our homes, offered a window into nature. Birding encouraged awareness of nature and of the ties between our homes and the world beyond, even in the center of the city, leading to an organised social reaction to our effect on wild birds: bird conservation.

Mahesh Rangarajan, University of Delhi, spoke of the historical links between nationalism and wild animals in India, particularly the Asian lions which were highly valued as royal and later 'national' animals. As their numbers have improved since Indian independence (1947), nationalism has been increasingly redirected toward the tigers, an even more endangered species.

Asian lions survived for so long in densely populated India because of the protection of their habitats by Mughal princes for hunting, then by the Raj for forestry, then since 1948 and the foundation of IUCN, as 'national parks'. This continuity has been very important to the 
survival of many rare species, including the snow leopard. Thought to be extinct, it was first photographed in India in 1972.

Harriet Ritvo, Massachusetts Institute of Technology, delved into the topic of "How wild is wild?" and explored the practices of the nineteenth-century acclimatisation societies, namely their attempts to breed and manipulate wild animals to fit human expectations. Their efforts sometimes blurred the line between wild and domestic animals and even among some domestic animals. She concluded by mentioning the initiative to save the Scottish wild cat which, ironically, benefited from the establishment of a studbook, a captive breeding program, and other measures that blur the cultural boundary between the wild and the domesticated, even as they attempt to reinforce the genetic boundary that separates them.

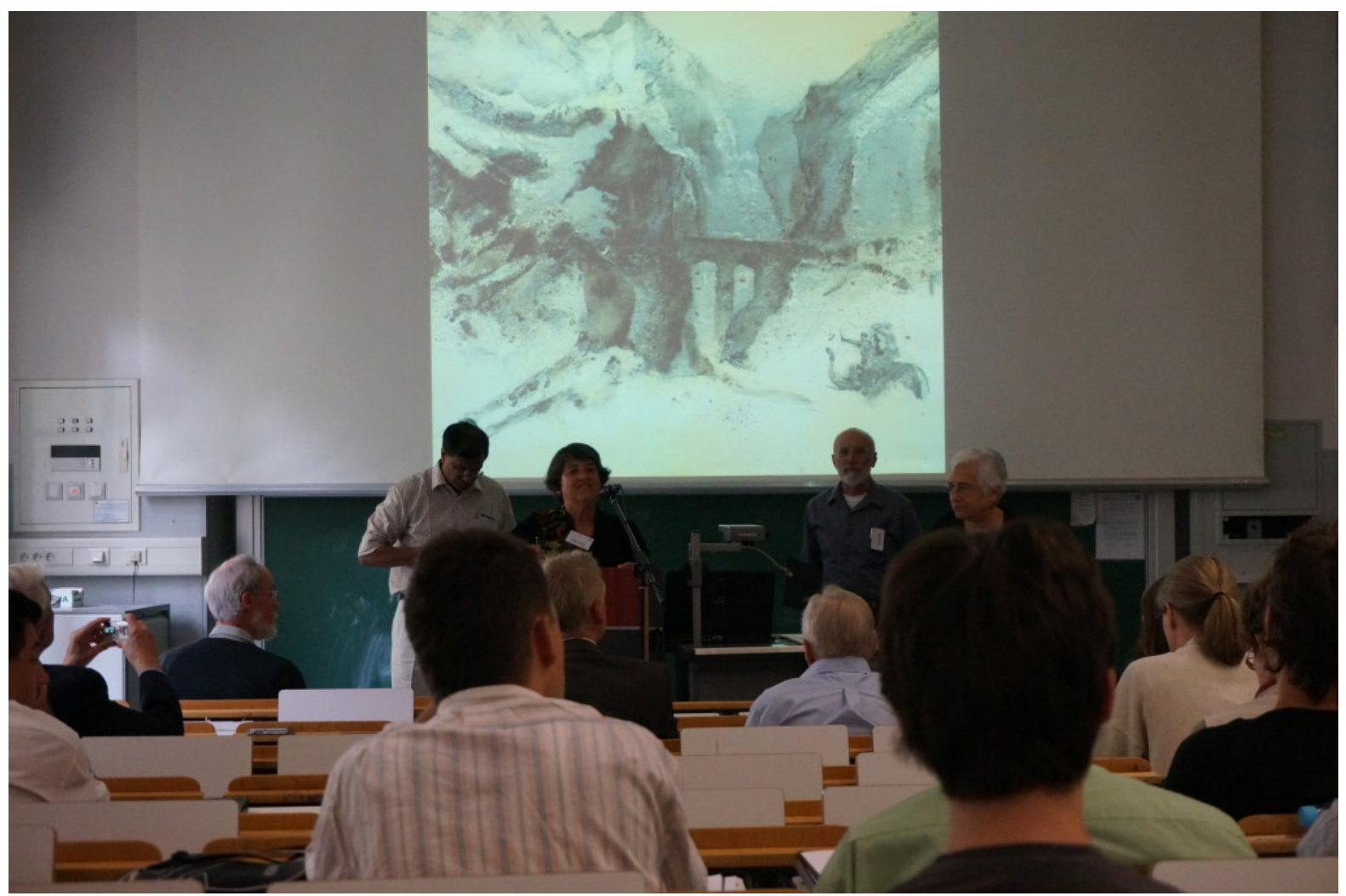

Edges of Environmental History panel

A third panel dealt with "Knowing Nature" and ideas around science.

William Beinart from the University of Oxford looked at some of the problems around the concepts of biodiversity and biocultural diversity for environmental historians. Referring to Carruthers' work on the genus Acacia, he took the opportunity to question the differing uses of terminology by natural scientists and historians with particular reference to nonindigenous species and the process of plant transfers.

He argued that biodiversity is frequently used as a nativist or purist concept with limited spatial applicability, lacking often a historical, social and cultural dimension, and that the term biocultural diversity may be useful to get at some of these complexities. He suggested a totalising approach to environmental history, a more descriptive environmental history that attempts to map the complexity of change and to evaluate it both in social and natural terms. 
Etienne Benson, University of Pennsylvania and Max Planck Institute for the History of Science, spoke about territories and territoriality among ornithologists and pondered on possible connections with discourses of territoriality that occurred at the same time in terms of the nation-state. His aim was to suggest the need to overcome the disciplinary divides separating the human and natural sciences, which continue to shape science and scholarship today, owing to the division of the world into two independent parts, typically identified asnature and culture. According to him, the resonance between theories of territory in bird life and the structure of the nation-state in the twentieth century was due to the shared situation - all at once biological, ecological, social, cultural, political, and economic - in which humans and other animals found themselves.

Saul Dubow, Queen Mary, University of London, introduced South African science into the conversation, citing Jan Smuts' use of the work of Alex du Toit (geologist and proponent of plate tectonics) and Raymond Dart (discoverer of an early hominid fossil) to provide a southern emphasis to the natural sciences. He drew comparisons with Jane Carruthers' exploration of what it means to be an African in an increasingly transnational world, signaling one of the main strengths of her approach as an environmental historian: the embracement of historical span while remaining keenly aware of the local contexts and institutions that affect the production of environmental and scientific knowledge.

Libby Robin, Australian National University, looked at Carruthers as a biographer and spoke about the use and branding of historical figures and their life histories by science, emphasising the importance of personalities and biography in understanding environmental developments and schools of thought. She gave the examples of Charles Elton (invasion biology), Aldo Leopold (restoration ecology), and C.S. (Buzz) Holling (resilience science), whose names have been used to bestow authority in their respective fields. The list ends with Rachel Carson, whose name was adopted by the sponsor of the workshop, underscoring the center's transnational and global dimensions, to draw more readers and writers into the conversation.

The fourth and final panel, "A commonwealth of ideas", covered some of the philosophical developments in environmental history.

Bron Taylor, University of Florida, discussed how protected areas are demarcated not only by physical boundaries but also by differing and sometimes incompatible perceptions. He drew the distinction between the "romantic narrative", recalling the romantic tradition of felt loss and longing for biologically pristine and diverse ecosystems, and the "critical narrative", who considers the first one a mask for elite or imperial power, privilege, and subjugation. Jane Carruthers has refused to embrace either narrative uncritically, recognising that there is a dialectical relationship between them, and showing that protected areas reflect materially and philosophically the societies in which they are situated. Taylor also came across this conclusion in his work at the California State Department of Parks and Recreation. $\mathrm{He}$ concluded by saying that environmental history must do more than criticise past failings and injustices. Rather, it must contribute to understanding processes, lifeways and livelihoods that promote healthy and resilient biocultural systems, producing paths toward a more equitable and sustainable future.

Lise Sedrez, Federal University of Rio de Janeiro, brought environmental justice firmly into the picture by comparing Jane Carruthers' research on the evictions of the residents of Lady Selborne (Pretoria) during apartheid and the evictions of the slum areas of Rio de Janeiro, focusing namely on the construction of a new community, Cidade de Deus, where displaced 
communities were relocated after several floods. She concluded advocating historians' capacity to bring back the communities' struggles and voices, to honor their strategies of survival, and to address historical urban injustice by working on their memories.

Christof Mauch reflected upon the concepts of exploitation and sustainability, two core terms in Jane Carruthers' thinking. He discussed how the notion of sustainability had possibly originated with the Venetians, aware of the scarcity of natural resources, and how the Old World's worries about it were brushed aside with colonisation, with the sudden availability of land and resources in the New World. According to him, the illusion of having enough space and resources was perhaps the tragedy of modern Western history, giving the feeling of boundlessness and taking away any sense of urgency. He concluded that if we are to use the experiences of history for the good of our future, it is important to evoke both positive images and warnings against destructive changes in the world, revealing to us both faulty decisions and new courses of action, precisely as Jane Carruthers' sustainable stories do.

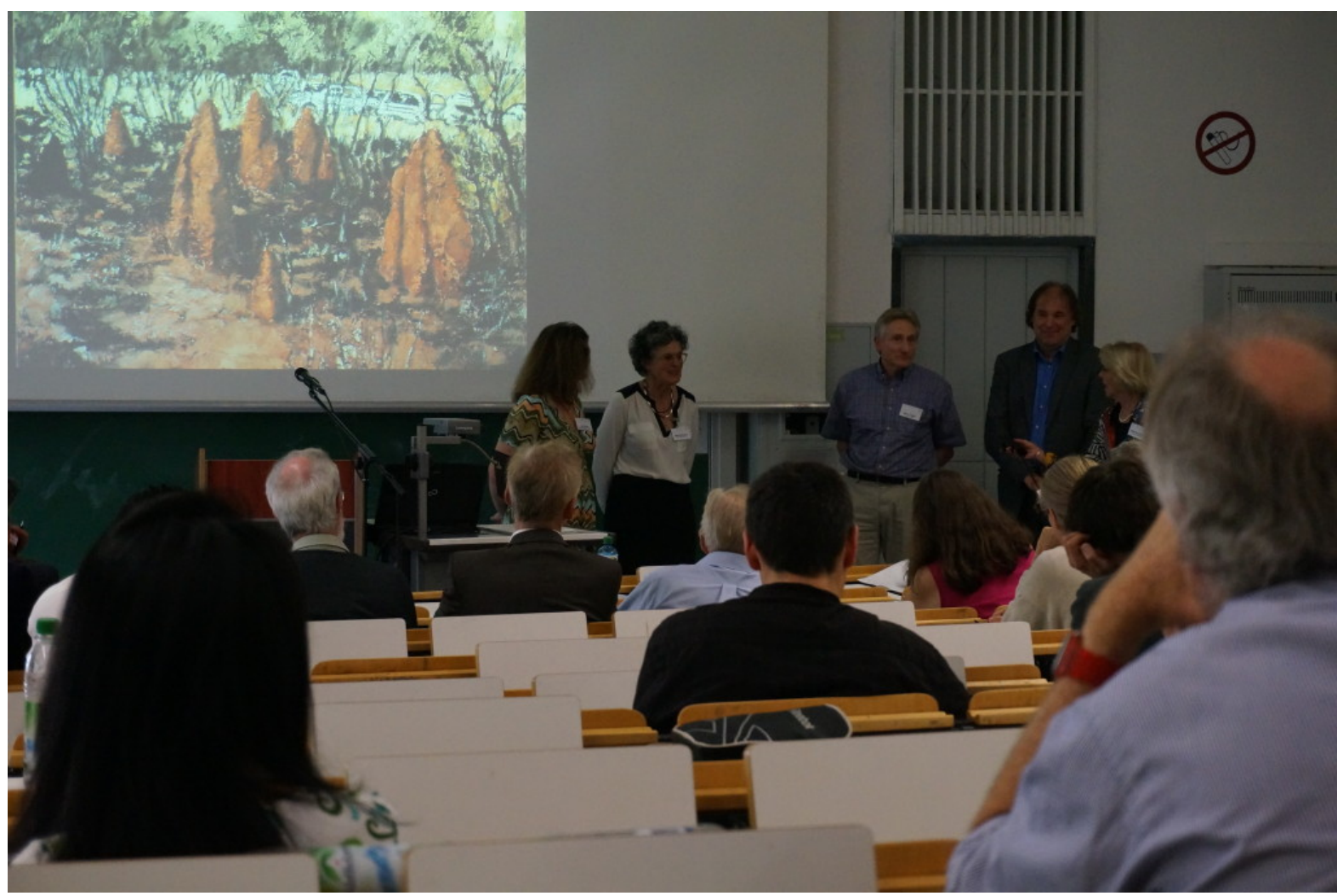

Final edges panel

At the end of the workshop, there was a presentation of the recently published Thomas Baines: Exploring Tropical Australia 1835 to 1857, edited by Jane Carruthers and Lindy Stiebel, which was presented to all the participants. 